\title{
Mechanical, Thermal and Morphological Behaviours of Polybutylene Terephthalate/Polycarbonate blend nanocomposites
}

\author{
P. R. Rajakumar ${ }^{1}$, R. Nanthini ${ }^{2}$ \\ ${ }^{1}$ Department of Chemistry, Government Arts College, Chidambaram, Tamil Nadu, India \\ ${ }^{2}$ Department of Chemistry, Pachayappa's College, Chennai, Tamil Nadu, India \\ Email address: prrajkkumar@gmail.com
}

\begin{abstract}
Polybutylene Terephthalate (PBT) / Polycarbonate (PC) nanocomposite blend was fabricated using melt blending technique in a twin extruder. The blend composition was optimized at PBT-PC weight ratio of 80-20. The effect of incorporation of various organically modified Montmorillonite (OMMT) and naturally occurring sodium Montmorillonite (MMT) on the mechanical, thermal and morphological properties of the nanocomposites blend has been investigated. It was observed that the Izod impact strength, tensile strength and flexural strength demonstrated a significant increase with the increase in clay loading from 1-7 weight \% due to homogeneous dispersion of clay within the blend matrix. Thermo gravimetric analysis (TGA) revealed an increase in thermal stability of the blend with the incorporation of nanoclay. There is also decrease in the melting temperature (Tm) and crystallisation temperature (Tc) as observed from DSC thermograms. DMA add the evidence for TGA, DSC and mechanical results. PBT - PC blend with clay exhibited featureless XRD indicative of exfoliated structure. TEM micrographs also confirm the same that the clay has exfoliated into individual layers.
\end{abstract}

Keywords: PBT; PC; TGA; DSC; DMA; XRD; TEM; Nanoclay; Untreated clay-MMT and organically modified clay-OMMT

\section{INTRODUCTION}

Blending of two or more polymers has emerged as an established route to design tailor made polymeric materials with desired attributes for various high performance applications ${ }^{1-4}$. However, most of the polymer pairs are inherently immiscible that results in incompatibility with subsequent phase separation in the blend matrix. Different approaches such as use of compatibilising agents, copolymers, grafting agents, reactive extrusion etc., have been the commonly used techniques to modify the interfacial region between the blends and increase the compatibility ${ }^{5,6}$.

More recently, PLS nanocomposites have attracted great interest both in industry and in academic, because they often exhibit remarkable improvements in properties when compared with virgin polymers or conventional micro and macro composites. These improvements can include high moduli ${ }^{7-12}$, increased strength and heat resistance ${ }^{13}$, decreased gas permeability ${ }^{14-18}$ and flammability ${ }^{19-23}$ and increased biodegradability of biodegradable 
polymers $^{24}$. Layered silicates, with its inherent high aspect ratio ranging from 100 to 2000 offers more surface contact per unit filler within the polymer matrix resulting in enhanced performance characteristics with a minimum loading of $3-5 \%{ }^{25}$.

The structures that are observed for layered silicate based nanocomposites can be defined as either intercalated or exfoliated. An intercalated structure results when the polymer penetrates into the galleries of the layered structure resulting in a highly ordered arrangement of alternating clay platelet and polymer layers. An exfoliated structure is formed when the layered silicates are delaminated. In this case individual silicate layers are completely dispersed in the continuous polymer matrix ${ }^{26,27}$.

However, large improvement in the mechanical properties is observed if clay platelets are well dispersed and exhibit an exfoliated morphology within the polymer matrix. To achieve an exfoliated structure, it is necessary to enhance the interactions between the polymer and filler. This can be achieved by surface treating the clay platelets.

PBT is one of the engineering plastics which have good combination of properties such as rigidity, hardness, abrasion, solvent resistance, electrical insulation and high rates of cyrstallisation that allow short cycle times in injection moulding ${ }^{28-30}$.

However, PBT is strongly notch sensitive, give low notched Izod impact strength ${ }^{31,32}$ and break in a brittle fashion when standard notched specimens are tested. Hence, PBT is fairly resistant to crack initiation but have only modest resistance to crack propagation. The strong notch sensitivity of PBT can be eliminated by the incorporation of impact modifiers ${ }^{33}$ such as, nanoclays or in general nanomaterials which increase the surface area which in turn increases the mechanical properties. Thus, polymer nanocomposites, at loading levels of 2-3 $\%$ of nanomaterials exhibit enhanced mechanical properties, improved thermal properties when compared with neat polymers or their blends ${ }^{34}$. The cost difference between the neat matrix and its polymer nanocomposites is about $10-15 \%$.

Many polymers like nylon ${ }^{35,36}$, polystyrene ${ }^{37-39}$, polypropylene ${ }^{40-43}$, polystyrene-coacrylonitrile $^{44}$, polyethylene-co-vinyl acetate ${ }^{45,46}, \mathrm{EVA}, \mathrm{PEO}^{47}$ have been studied recently by incorporating clay nanocomposites. Blends based on PC and PBT have received much commercial attention for the last 20-30 years, especially in the automotive industry ${ }^{48-57}$. PC is a good engineering plastic. It has high creep resistance over a broad temperature range, excellent toughness and dimensional stability, good impact resistance at even small thickness and good properties retention even up to $-20^{\circ} \mathrm{C}$. PC has a good balance of properties which include high modulus and strength, heat deflection temperature and toughness. However, it has poor solvent and hydrolysis resistance. Therefore, PBT is blended with PC to improve the chemical resistance to moulded parts. In the present work, it has been attempted to prepare exfoliated nanocomposites with PBT/PC blend.

\section{EXPERIEMENTAL}

\section{1. Materials}

The polymer matrix used in this research is a commercial PBT (DUPONT $^{\mathrm{TM}}$ CRASTIN $^{\circledR}$ S610SF NC010). PC was supplied by GE plastics under the trade name of Lexan ${ }^{\circledR}$ F2000. The filler was sodium montmorillonite (MMT) unmodified clay having CEC $92.6 \mathrm{meq} / 100 \mathrm{~g}$ of clay and modified clay (cloisite ${ }^{\circledR}$ 20A) (MMT modified by 2M2HT dimethyl dehydrogenated Tallow, quaternary ammonium - OMMT) having CEC of 95 meq/100g of clay were obtained from M/s Southern Clay Products Inc, USA. (HT is made of approximately $65 \% \mathrm{C}_{18} \mathrm{H}_{37}, 30 \% \mathrm{C}_{16} \mathrm{H}_{33}$ and $\left.5 \% \mathrm{C}_{14} \mathrm{H}_{2} 9\right)$. PBT was blended with $\mathrm{PC}$ in 
different ratios like 90-10, 80-20 and 70-30. From the experimental results, $80 \%$ weight of PBT gives better results with $20 \%$ weight of PC and it was considered as an optimized ratio.

Fillers MMT and OMMT were incorporated in the ratio of $1 \%, 3 \%, 5 \%$ and $7 \%$ by weight with $80 \%$ PBT toughened by $20 \%$ PC.

\section{2. Preparation of Blends}

Initially PBT and PC were blended without filler, to get 90-10, 80-20 and 70-30 weight ratio to establish optimized blend ratio. Based on the tensile and impact strength, the optimized percentage of PC is $20 \%$ by weight. Then PBT/PC 80:20 blend mixture was mixed with two different nanoclays - one untreated clay called sodium montmorillonite (MMT) and the other is treated clay or organically modified clay called (cloisite ${ }^{\circledR}$ 20A) (OMMT) with different ratios such as $1 \%, 3 \%, 5 \%$ and $7 \%$. $7 \%$. PBT was dried at $100{ }^{\circ} \mathrm{C}$ in an air circulated oven for 8 hours prior to blending. The blend was prepared via melt compounding method using twin screw extruder (Bersfort FRG Germany) at temperature range of $220^{\circ} \mathrm{C}$ with a screw speed of $150 \mathrm{rpm}$. After the extrusion, the extrudate was cooled in water bath and palletized. Finally these granules were injection molded as per ASTM using SP130 injection molding machine (Windsor, India) having clamping force 100T fitted with dehumidifier at a temperature range of $250-285^{\circ} \mathrm{C}$.

\subsection{Mechanical properties}

The tensile tests were performed according to ASTM D 638 using SHIMADZU AUTOGRAPH (model AG 50 RNISD MS) at room temperature of $23 \pm 1{ }^{\circ} \mathrm{C}$. The gauge length was set as $50 \mathrm{~mm}$ and the cross head speed was $50 \mathrm{~mm} / \mathrm{min}$. Tensile strength, tensile modulus and elongation at break were recorded. The flexural properties of all the composites were measured with a Lloyd instruments Ltd, LR $100 \mathrm{KN}$, UK machine according to ASTM D 790 with a cross head rate of $2.82 \mathrm{~mm} / \mathrm{min}$. Izod impact strength was measured with a (ATS FAAR, Italy) impact tester according to ASTM D 256, method-A with notched samples. Five replicate specimens were used for each test and the data reported are the average of five tests.

The density measurements are carried out for all the PBT blend nanocomposite samples prepared as per ASTM D 1505. MFI, as per ASTM D 1238 was carried out for all the PBT blend nanocomposite samples. As per ASTM D 257, the volume resistivity and surface resistivity were measured for all the samples prepared. The dielectric strength experiment was carried out as per ASTM D 149 on all the PBT blend nanocomposite samples.

\section{4. Thermo Gravimetric Analysis (TGA)}

It is commonly used to monitor polymer degradation reactions. TGA involves monitoring weight as a function of time. The thermal stability of the samples prepared was assessed. TGA were performed in a Perkin Elmer, USA PYRIS ITGAC under $\mathrm{N}_{2}$ atmosphere. The temperature range was $50{ }^{\circ} \mathrm{C}$ to $900{ }^{\circ} \mathrm{C}$ at a heating rate of $20{ }^{\circ} \mathrm{C} / \mathrm{min}$ and corresponding weight loss was recorded. 


\section{5. Differential Scanning Calorimetry (DSC)}

The DSC scans were carried out by using a Perkin Elmer (Diamond DSC) calorimeter in a nitrogen atmosphere. The sample was first heated from $50{ }^{\circ} \mathrm{C}$ to $300{ }^{\circ} \mathrm{C}$ at $10{ }^{\circ} \mathrm{C} / \mathrm{min}$ and cooling rate was controlled at $10{ }^{\circ} \mathrm{C} / \mathrm{min}$ from $300{ }^{\circ} \mathrm{C}$ to $50{ }^{\circ} \mathrm{C}$. In order to measure the energies of melting, indium was used as standard.

\section{6. Dynamic Mechanical Analysis (DMA)}

Dynamic Mechanical Analysis (DMA) was performed using Netzsch DMA 242 in three points bending mode at frequency of $1 \mathrm{~Hz}$ and $120 \mu \mathrm{m}$ over a temperature range of -50 ${ }^{\circ} \mathrm{C}$ to $150{ }^{\circ} \mathrm{C}$ at a heating rate of $10^{\circ} \mathrm{C} / \mathrm{min}$.

\section{7. X- Ray Diffraction Analysis (XRD)}

Both for the clay and nanocomposites, XRD was recorded using Philips X' pert MPD, Japan make, which had a graphite monochromator and $\mathrm{Cu} \mathrm{K} \alpha$ radiation source and was operated at $40 \mathrm{kV}$ and $30 \mathrm{~mA}$.

\section{8. TEM Analysis}

TEM analysis of the specimens was carried out using JEOL JEM 2100 HRTEM. The HRTEM has LaB6 Filament and acceleration voltage of $200 \mathrm{kV}$. Ultra thin sections of sample were prepared employing ULTRACUT UCT LEICA MICRO SYSTEM microtome with a diamond knife at temperature of $-60{ }^{\circ} \mathrm{C}$ at $\mathrm{N}_{2}$ atmosphere.

\section{RESULTS AND DISCUSSION}

\section{1. Effect of loading PC on mechanical properties of PBT}

The mechanical properties, among all the properties of plastic materials, are often the most important properties because virtually all service conditions and the majority of end-use applications involve mechanical loading ${ }^{58}$. Impact strength is toughness as a property of plastics probably most useful to consider ${ }^{59}$. While it is possible to perform impact tests and to rank a series of plastic materials, it is impossible to predict whether the material will serve satisfactorily under the working conditions. The factors which may influence are additives, impurities, temperature, geometry, orientation and morphology, surface condition, energy and speed of any impacting blow, the environment and the strains due to external loads. PC was added in small weight proportions like $10 \%, 20 \%$ and $30 \%$ to PBT to watch out the changes in mechanical properties of PBT.

It is evident from the Table 1 as the content of $\mathrm{PC}$ increases, the impact strength also increases up to PBT-PC 80-20 weight ratio, and then for PBT-PC 70-30 weight ratio, impact strength decreases showing that PBT-PC 80-20 weight ratio is the optimised ratio for toughness. The increase in Izod impact strength is probably due to the PC effectively dispersed in PBT matrix there by leading to dissipation of more impact energy.

Tensile strength increases moderately and the increase is pronounced upto PBT-PC 80-20 weight ratio after then the increase is only marginal. Flexural strength is also on increasing trend and it is more pronounced upto PBT-PC 80-20 weight ratio. While the increase is $17 \%$ up to $80-20$ ratio, it is only a $5 \%$ rise for $70-30$ ratio. Tensile modulus and flexural modulus values also increase upto 80-20 ratio of PBT-PC, after which the values fall down. 
Table 1. Effect of loading PC with PBT on mechanical properties.

\begin{tabular}{|c|c|c|c|c|c|}
\hline $\begin{array}{c}\text { PBT/PC } \\
\text { weight } \\
\text { ratio }\end{array}$ & $\begin{array}{c}\text { Izod impact } \\
\text { strength } \\
\mathbf{J} / \mathbf{m}\end{array}$ & $\begin{array}{c}\text { Tensile } \\
\text { strength } \\
\mathbf{M P a}\end{array}$ & $\begin{array}{c}\text { Flexural } \\
\text { strength } \\
\mathbf{M P a}\end{array}$ & $\begin{array}{c}\text { Tensile } \\
\text { modulus } \\
\mathbf{G P a}\end{array}$ & $\begin{array}{c}\text { Flexural } \\
\text { modulus } \\
\mathbf{G P a}\end{array}$ \\
\hline $100: 0$ & 50 & 50 & 71 & 2.43 & 2.17 \\
$90: 10$ & 93 & 56 & 76 & 3.19 & 3.45 \\
$80: 20$ & 144 & 58 & 83 & 4.95 & 3.93 \\
$70: 30$ & 111 & 59 & 87 & 2.94 & 3.54 \\
\hline
\end{tabular}

Thus, all the five properties, on addition of PC, increases from the virgin PBT showing that there is effective dispersion of PC in PBT matrix has occurred and in particular, up to a ratio of PBT-PC 80-20. Impact modified PC/PBT blends have indicated good interfacial adhesion between the PC and PBT phases ${ }^{60}$.

\section{2. Effect of loading clay with PBT-PC 80-20 on mechanical properties}

$1 \%, 3 \%, 5 \%$ and $7 \%$ weight ratio of MMT clay and OMMT clay were added to each of the optimised 80-20 weight ratio of PBT-PC blends. It is evident from the Table 2 that impact strength increases steadily with the addition of MMT to PBT-PC 80-20 blend. The value reaches a maximum of $161 \mathrm{~J} / \mathrm{m}$ for the addition of $5 \%$ of MMT clay and then it decreases for the addition of $7 \%$ weight of MMT clay. Thus, the values of impact strength reach almost a three fold from the pure PBT for the addition of $5 \%$ of MMT.

Similarly, for every addition of OMMT clay to the optimised ratio of PBT-PC 80-20 blend, the value of impact strength increases and reaches a value of $268 \%$ rise for the addition of $5 \%$ weight of OMMT clay and then it decreases for the addition of $7 \%$ weight of OMMT clay which is still $250 \%$ rise from the virgin PBT value but the effect is significantly more in the case of OMMT clay.

The value of tensile strength increases upto the addition of $5 \%$ of clay, and then it decreases for the addition of $7 \%$ of clay. The increase is more pronounced with the addition of $5 \%$ OMMT clay. The value of flexural strength shows an increasing trend for both MMT clay as well as OMMT clay, but the rise is not that much pronounced as it is observed in the values of impact and tensile strengths.

The value for tensile modulus decreases upto the addition of $7 \%$ clay while the flexural modulus values also show the same trend. It is clear that addition of $5 \%$ MMT clay and addition of $5 \%$ OMMT clay gives the better result compared with the virgin PBT or PBT-PC 80-20 blend ratio.

The better compatibility of OMMT with PBT-PC blend matrix than MMT is evident from the results obtained. It is noteworthy to mention that for successful formation of polymer clay nanocomposites, alteration of the clay polarity has helped OMMT to incorporate in a better way to the polymer matrix which is done by organic modification of the clay. 
Table 2. Effect of loading clay with PBT-PC 80-20 blend on mechanical properties.

\begin{tabular}{|c|c|c|c|c|c|c|c|c|}
\hline \multicolumn{3}{|c|}{$\begin{array}{c}\text { percentage } \\
\text { weight ratio } \\
\text { of }\end{array}$} & \multirow{2}{*}{$\begin{array}{l}\text { clay } \\
\text { type }\end{array}$} & \multirow{2}{*}{$\begin{array}{c}\text { Izod } \\
\text { impact } \\
\text { strength } \\
\mathbf{J} / \mathbf{m}\end{array}$} & \multirow{2}{*}{$\begin{array}{c}\text { Tensile } \\
\text { strength } \\
\text { MPa }\end{array}$} & \multirow{2}{*}{$\begin{array}{c}\text { Flexural } \\
\text { strength } \\
\text { MPa }\end{array}$} & \multirow{2}{*}{$\begin{array}{c}\text { Tensile } \\
\text { modulus } \\
\text { GPa }\end{array}$} & \multirow{2}{*}{$\begin{array}{c}\text { Flexural } \\
\text { modulus } \\
\text { GPa }\end{array}$} \\
\hline PBT & PC & clay & & & & & & \\
\hline 80 & 20 & 0 & ---- & 144 & 58 & 83 & 4.95 & 3.93 \\
\hline 80 & 20 & 1 & MMT & 145 & 61 & 82 & 2.452 & 3.066 \\
\hline 80 & 20 & 3 & MMT & 148 & 67 & 85 & 1.652 & 3.086 \\
\hline 80 & 20 & 5 & MMT & 161 & 78 & 87 & 1.313 & 3.274 \\
\hline 80 & 20 & 7 & MMT & 156 & 70 & 83 & 1.214 & 3.047 \\
\hline 80 & 20 & 1 & OMMT & 162 & 66 & 85 & 2.125 & 3.231 \\
\hline 80 & 20 & 3 & OMMT & 169 & 70 & 88 & 1.377 & 3.193 \\
\hline 80 & 20 & 5 & OMMT & 189 & 81 & 95 & 1.696 & 3.288 \\
\hline 80 & 20 & 7 & OMMT & 174 & 69 & 86 & 1.014 & 3.111 \\
\hline
\end{tabular}

Significant PBT impact improvement was achieved with the addition of 25-50 weight $\%$ of $\mathrm{PU}^{61}$. It has been reported that at loading levels of 2-3\% clay, polymer nanocomposites offer similar performance to conventional polymeric composites with $30-50 \%$ of reinforcing material $^{62}$. PP/ethylene-octene-copolymer blend nanocomposites on incorporation of C $20 \mathrm{~A}$ nanoclays showed higher tensile strength and modulus, flexural strength and modulus and impact strength ${ }^{63}$. PA-6 nanocomposites had superior mechanical properties than PA- $66^{64}$.

\section{3. Effect of loading clay with PBT-PC 80-20 blend on Density}

Density ${ }^{65}$ is a measure of the fluffiness of a material. Density assures the product uniformity. Table 3 gives the measured density values of PBT-PC nanocomposites. All nanocomposites have the density value between 1.25 and 1.35. Incorporation of MMT clay and OMMT clay increases the density value slightly higher than the remaining samples. OMMT clay due to their organic moiety in the clay might have increased the value of density.

\section{3 .4. Effect of loading clay with PBT-PC 80-20 blend on MFI}

MFI measures the rate of extrusion of thermoplastic material through an orifice of specific length and diameter under prescribed conditions of temperature and pressure. MFI is primarily used as a means of measuring the uniformity of the flow rate of the materials. MFI is an inverse measure of molecular weight ${ }^{66}$. 
Table 3. MFI, density and Electrical properties of PBT-PC nanocomposites.

\begin{tabular}{|l|c|c|c|c|c|}
\hline \multicolumn{1}{|c|}{ Polymer type } & $\begin{array}{c}\text { Melt flow } \\
\text { index } \\
\mathrm{g} / 10 \mathrm{~min}\end{array}$ & $\begin{array}{c}\text { Density } \\
\mathrm{g} / \mathrm{cc}\end{array}$ & $\begin{array}{c}\text { Dielectric } \\
\text { strength } \\
\mathrm{KV} / \mathrm{mm}\end{array}$ & $\begin{array}{c}\text { Surface } \\
\text { resistivity } \\
10 \\
\text { ohm.cm }\end{array}$ & $\begin{array}{c}\text { Volume } \\
\text { resistivity } \\
10^{16} \mathrm{~cm}\end{array}$ \\
\hline $100 \%$ PBT & 43.620 & 1.306 & 16.00 & 3.000 & 6.200 \\
\hline $90 \%$ PBT 10\% PC & 39.369 & 1.291 & 15.80 & 3.140 & 6.160 \\
\hline $80 \%$ PBT 20 \% PC & 35.522 & 1.287 & 16.20 & 2.980 & 6.308 \\
\hline $70 \%$ PBT 30 \% PC & 31.042 & 1.278 & 15.60 & 2.880 & 6.150 \\
\hline $80 \%$ PBT 20\% PC 1 \% MMT clay & 17.052 & 1.262 & 16.60 & 3.154 & 6.248 \\
\hline $80 \%$ PBT 20\% PC 3 \% MMT clay & 16.990 & 1.286 & 16.90 & 3.090 & 6.342 \\
\hline $80 \%$ PBT 20\% PC 5 \% MMT clay & 16.850 & 1.294 & 16.80 & 3.020 & 6.356 \\
\hline $80 \%$ PBT 20\% PC 7 \% MMT clay & 16.618 & 1.291 & 16.71 & 3.011 & 6.329 \\
\hline $80 \%$ PBT 20\% PC 1 \% OMMT clay & 16.315 & 1.343 & 17.51 & 3.182 & 6.311 \\
\hline $80 \%$ PBT 20\% PC 3 \% OMMT clay & 16.230 & 1.323 & 17.32 & 3.120 & 6.351 \\
\hline $80 \%$ PBT 20\% PC 5 \% OMMT clay & 16.010 & 1.312 & 17.06 & 3.110 & 6.379 \\
\hline $80 \%$ PBT 20\% PC 7 \% OMMT clay & 15.845 & 1.295 & 16.98 & 2.996 & 6.294 \\
\hline
\end{tabular}

Measured MFI values for PBT-PC blends and PBT-PC nanocomposites are given in Table 3. For the addition of PC to PBT, MFI value decreases. The addition of clay brings an enormous decline in the value of MFI. Thus, the addition of clay has decreased the viscosity of the medium enormously from the pure PBT as well as PBT-PC blend matrix. Sodium montmorillonite is a high molecular weight material and the organically modified clay adds the organic moiety to the weight of clay part and the MFI values reflect the same in their results of blends, imparted with OMMT clay. Thus in short, addition of clay reduces the value for MFI.

\section{5. Electrical properties of PBT-PC 80-20 blend with clay loading}

The primary function of plastics in electrical applications is as an insulator. An insulator must have a high dielectric strength to withstand an electric field between the conductors. The key electrical properties of interest in the case of polymer materials are dielectric strength, volume resistivity and surface resistivity. High volume resistance materials are desirable in applications.

Table 3 gives the measured values of dielectric strength, volume resistance and surface resistance of the PBT-PC blends and PBT-PC 80-20 blend incorporated with MMT clay and OMMT clay.

All the samples possess high dielectric strength, high volume resistivity values and high surface resistivity values. Hence, PBT-PC clay nanocomposites can act as good insulator. Thus, the basic polymer PBT used in the present work has retained its good electrical properties after the addition of clay too.

\section{THERMAL STUDIES}

Thermal analysis plays a vital role in the characterization of polymer ${ }^{67}$. Knowledge of thermal behaviour is not only characterisation of materials especially for thermal stability and for selection of appropriate end users. 


\section{1. Thermo gravimetric analysis}

TGA involves heating a sample to some temperature and then monitoring its weight as a function of time. Change in weight, result from bond forming or breaking at elevated temperatures ${ }^{68,69-75}$. TGA is commonly used to monitor polymer degradation reactions.

\section{1. 1. Effect of loading clay with PBT-PC 80-20 blend in TGA}

The TGA thermograms of PBT-PC 80-20 nanocomposites with MMT and OMMT clay in $3 \%$ and $5 \%$ weight ratios are given in Fig. 1 and 2 and associated TGA derived parameters obtained from these thermograms are summarised in Table 4. During the thermal degradation, the TGA curves displayed a single step degradation process in all the cases and the sample weight in percentage decreases continuously to a residual level after mass loss has commenced. For PBT-PC blend and its nanocomposites, the onset of degradation temperature of PBT-PC 80-20 weight ratio blend has decreased from the value of pure PBT. Thus, the addition of PC to PBT in the weight ratio of $20 \%$ has decreased the thermal stability of virgin PBT.

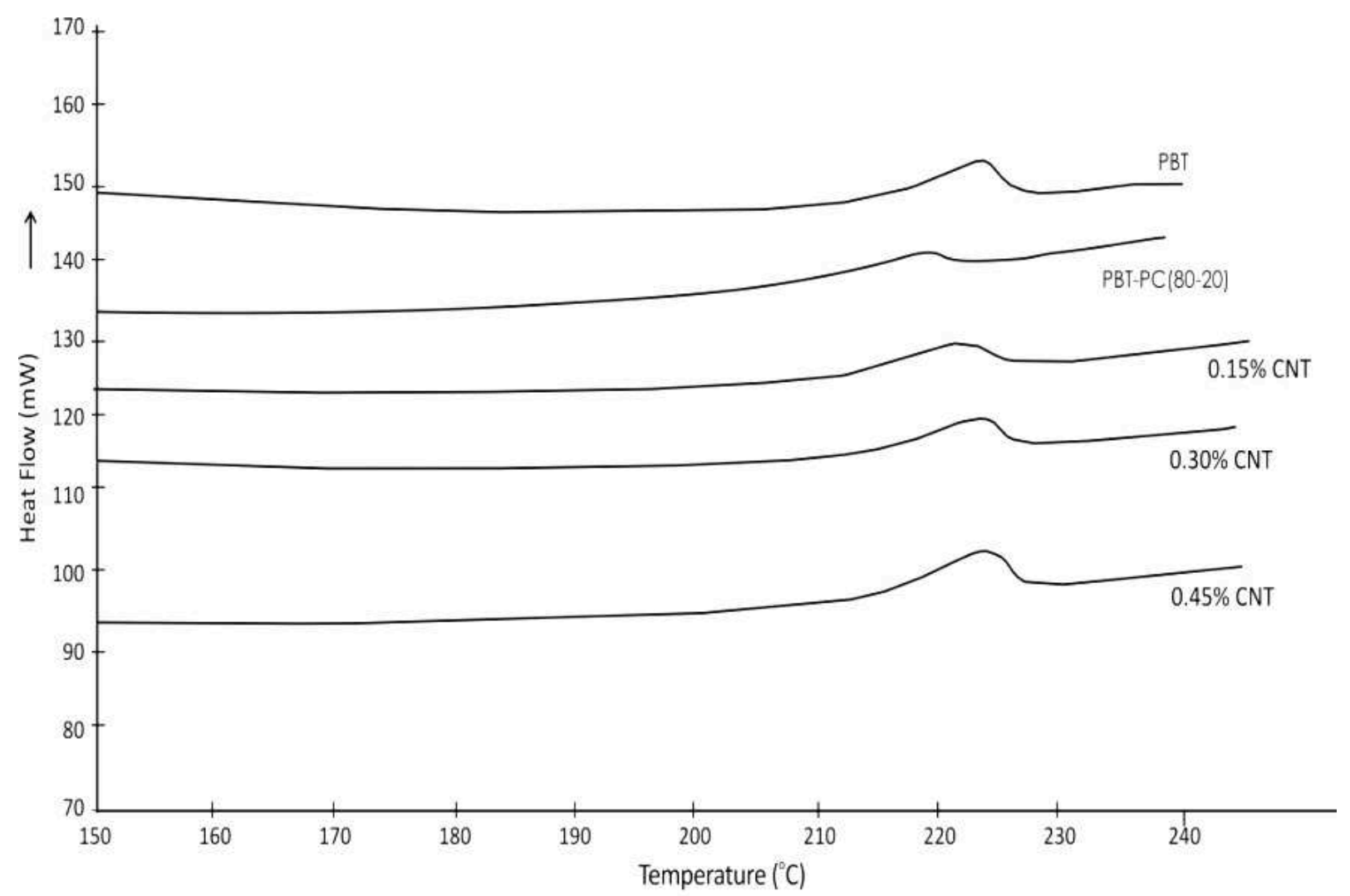

DSC (Tm) of PBT-PC 80-20 blend with carbon nanotubes

Fig. 1. DSC (Tm) of PBT-PC 80-20 blend with their Nanotube composites.

On the addition of MMT clay, the temperature for the onset of degradation, T-90 \%, $\mathrm{T}-80 \%, \mathrm{~T}-70 \%, \mathrm{~T}-60 \%, \mathrm{~T}-50 \%$ and end of degradation temperature increases showing higher stability than PBT-PC 80-20 blend. On adding $3 \%$ and $5 \%$ weight ratios of OMMT, there is further increase of temperature in all the cases. Thus, addition of both types of clay to PBT-PC 80-20 weight ratio, has improved the thermal stability considerably. $5 \%$ OMMT 
clay disperses with PBT-PC matrix effectively and hence the increased thermal stability is observed than the corresponding blends with MMT clay at both weight ratios of $3 \%$ and $5 \%$ and the same has been reflected in the study of mechanical properties also. The improved thermal stability of polymer /clay nanocomposites is mainly due to the formation of char which hinders the out-diffusion of the volatile decomposition products, as a direct result of the decrease in permeability, usually observed in exfoliated nanocomposites ${ }^{76,77}$. On higher clay concentration, much more exfoliated clay is formed; charring occurs easily and effectively, and consequently the thermal stability of the nanocomposites is enhanced.

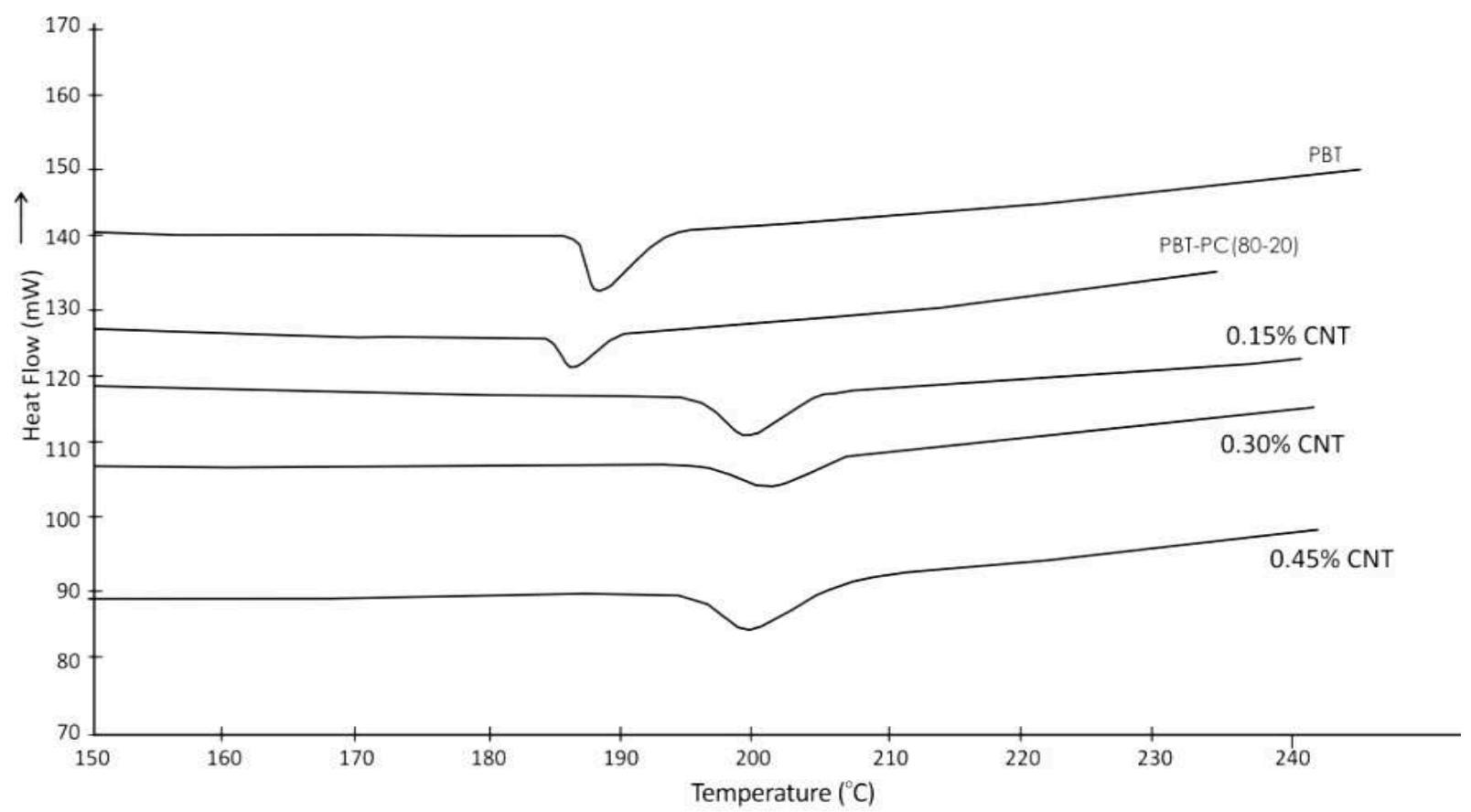

DSC (TC) of PBT-PC 80-20 blend with carbon nanotubes

Fig. 2. DSC (Tc) of PBT-PC 80-20 blend with their Nanotube composites.

Table 4. TGA data of PBT, PBT-PC 80-20 blend and their nanocomposites.

\begin{tabular}{|c|c|c|c|c|c|c|c|c|}
\hline Polymer type & $\begin{array}{c}\text { Onset of } \\
\text { degradation } \\
\text { temperature } \\
{ }^{\circ} \mathrm{C} \\
\end{array}$ & $\begin{array}{c}\mathrm{T}-90 \% \\
{ }^{\circ} \mathrm{C}\end{array}$ & $\begin{array}{c}\mathrm{T}-80 \% \\
{ }^{\circ} \mathrm{C}\end{array}$ & $\begin{array}{c}\mathrm{T}-70 \% \\
{ }^{\circ} \mathrm{C}\end{array}$ & $\begin{array}{c}\mathrm{T}-60 \% \\
{ }^{\circ} \mathrm{C}\end{array}$ & $\begin{array}{c}\mathrm{T}-50 \% \\
{ }^{\circ} \mathrm{C}\end{array}$ & $\begin{array}{c}\text { End of } \\
\text { degradation } \\
\text { temperature } \\
{ }^{\circ} \mathrm{C} \\
\end{array}$ & $\begin{array}{c}\text { Residue } \\
\text { percentage }\end{array}$ \\
\hline $100 \%$ PBT & 393 & 395 & 401 & 407 & 412 & 416 & 432 & 0 \\
\hline $80 \%$ PBT $20 \%$ PC & 364 & 384 & 395 & 404 & 410 & 415 & 431 & 7.3 \\
\hline $80 \%$ PBT $20 \%$ PC $3 \%$ MMT clay & 375 & 385 & 399 & 407 & 414 & 419 & 436 & 5.4 \\
\hline $80 \%$ PBT $20 \%$ PC $5 \%$ MMT clay & 380 & 387 & 398 & 406 & 412 & 417 & 436 & 5.8 \\
\hline $80 \%$ PBT $20 \%$ PC $3 \%$ OMMT clay & 384 & 391 & 401 & 411 & 415 & 421 & 441 & 5.0 \\
\hline $80 \%$ PBT $20 \%$ PC $5 \%$ OMMT clay & 390 & 392 & 403 & 411 & 418 & 423 & 442 & 4.6 \\
\hline
\end{tabular}




\section{2. Differential scanning calorimetry}

DSC is one of the most important tools used to investigate the thermal properties of the polymers. Melting temperature Tm, crystalline temperature Tc, enthalpy of melting $\Delta \mathrm{Hm}$ and percentage of crystallinity Xc has been detected from DSC thermograms.

\section{2. 1. Effect of loading clay with PBT-PC 80-20 blend}

Percentage of crystallinity, Xc was calculated, taking into consideration that $100 \%$ PBT has a heat of fusion value of $142 \mathrm{~J} / \mathrm{g}^{78}$.

It is evident from Fig. 3 and 4 that the DSC thermograms of the virgin matrices, blend matrices as well as the blend nanocomposite systems depicted single melting endotherms at a relatively constant melting temperature of about $220^{\circ} \mathrm{C}$. From the Table 5 , it is observed that the Tm of pure PBT is the highest and on the addition of $20 \%$ PC to pure PBT, the Tm decreases. For clay nanocomposites, Tm is lower than the pure PBT. The nanocomposites do not show much variation in their Tm.

Pure PBT exhibits Tc at $188^{\circ} \mathrm{C}$. The PBT-PC 80-20 blend and all its nanocomposites show their Tc values lower than that of pure PBT. Thus, the addition of clay decreases both Tm and Tc.

Out of the two clays, OMMT clay brings about more effective decrease in Tm and Tc than MMT clay. Addition of MMT clay enhances the crystallinity. The enhancement of crystallinity is more on adding OMMT when compared to MMT. A lower Tc implies slower crystallisation rate, which is attributed to the clay acting as the compatibilisers. The stronger interactions between the clay and PBT-PC matrix restricted the movements of chain segments, thus decelerating the rate of crystallisation.

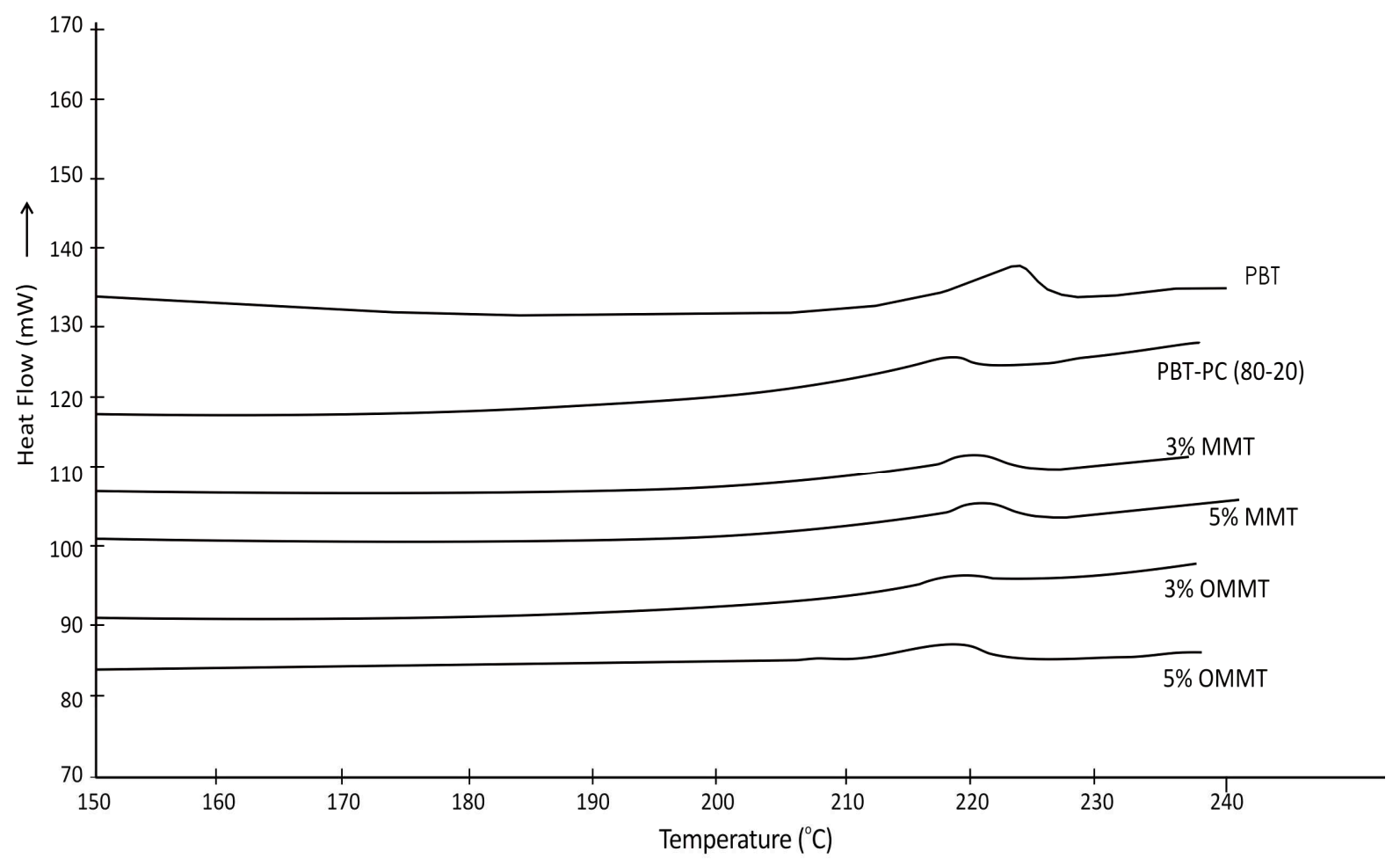

Fig. 3. DSC (Tm) of PBT-PC 80-20 blend with their nanocomposites. 


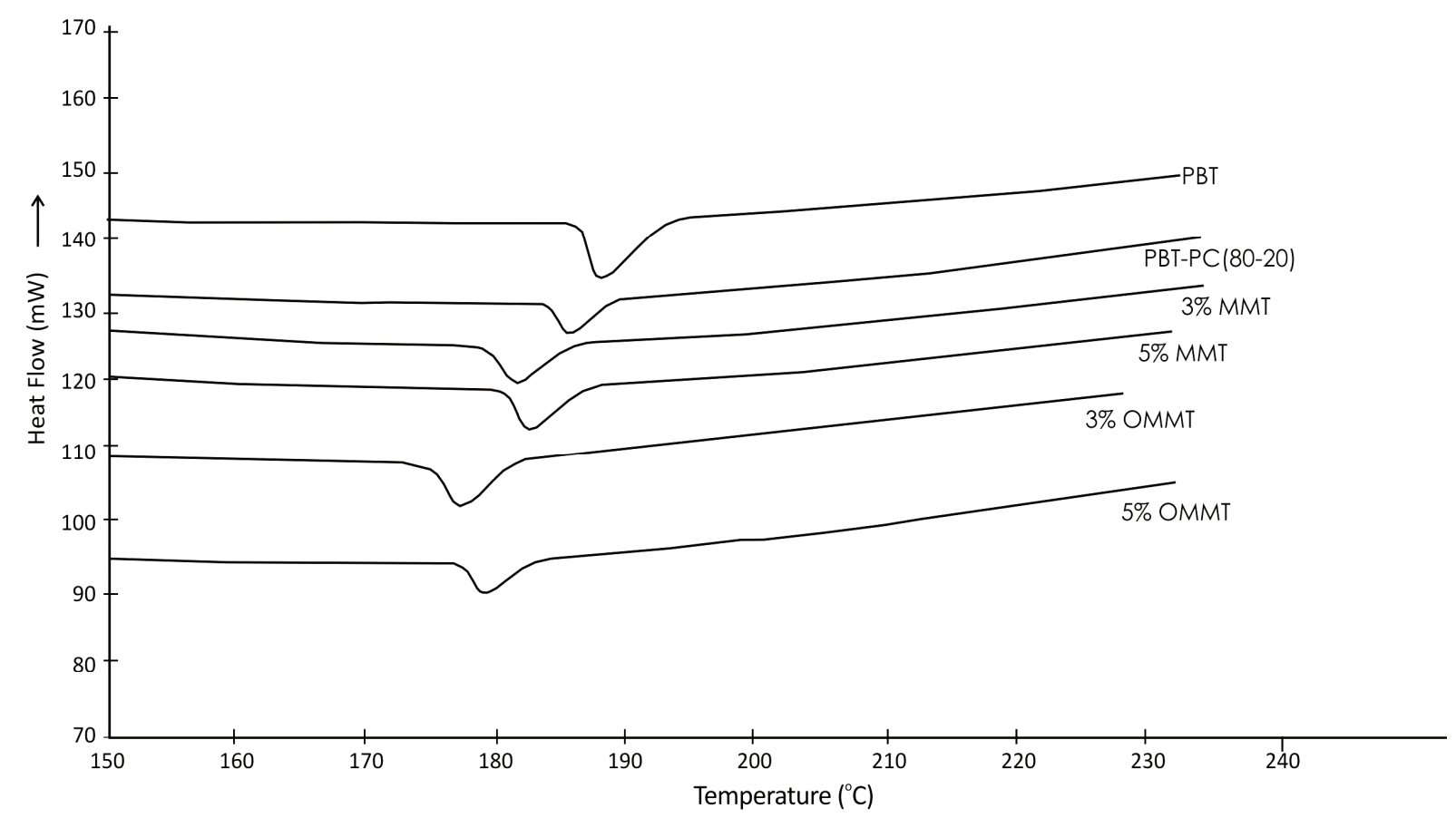

Fig. 4. DSC (Tc) of PBT-PC 80-20 blend with their nanocomposites.

It is interesting to note that the degree of crystallinity of PBT increased in the presence of OMMT. This is attributed to the nucleation effects of OMMT resulting in the improvement, in the crystal perfection of $\mathrm{PBT}^{79}$. A similar observation was reported by Mohd Ishak et al., for the injection moulded short glass fiber reinforced PBT composites ${ }^{80}$.

It can be seen that the melting point of PBT shifts to lower temperature with introduction of PC and nanoclay to the blend. This shows that, the miscibility of PBT and PC with clay has been improved, one of the criterion for the depression of $\mathrm{Tm}^{81}$. The shift of PBT melting peak to lower temperature is believed to originate from the compatibilisation.

The increased interaction with the clay hinders the process of crystallisation and crystal growth $^{82}$. PBT is one of the fastest crystallising polymers and this has been explained in terms of low nuclear density of $\mathrm{PBT}^{83}$.

Table 5. DSC data of PBT, PBT-PC 80-20 blend and their nanocomposites.

\begin{tabular}{|l|c|c|c|c|}
\hline \multicolumn{1}{|c|}{ Polymer type } & $\begin{array}{c}\text { Melting } \\
\text { temperature } \\
\mathrm{Tm}{ }^{\circ} \mathrm{C}\end{array}$ & $\begin{array}{c}\text { Heat of } \\
\text { fusion } \\
\mathrm{H}_{\mathrm{f}} \mathrm{J} / \mathrm{g}\end{array}$ & $\begin{array}{c}\text { Crystallisation } \\
\text { temperature } \\
\mathrm{Tc}{ }^{\circ} \mathrm{C}\end{array}$ & $\begin{array}{c}\text { Percentage of } \\
\text { crystallinity } \\
\text { Xc }\end{array}$ \\
\hline $100 \%$ PBT & 224.25 & 21.63 & 188.04 & 15.23 \\
$80 \%$ PBT 20 \% PC & 219.49 & 7.80 & 185.62 & 5.49 \\
$80 \%$ PBT 20 \% PC 3 \% MMT clay & 220.85 & 8.92 & 181.12 & 6.28 \\
$80 \%$ PBT 20 \% PC 5 \% MMT clay & 221.34 & 10.91 & 182.06 & 7.68 \\
$80 \%$ PBT 20 \% PC 3 \% OMMT clay & 219.63 & 13.23 & 178.00 & 9.32 \\
$80 \%$ PBT 20 \% PC 5 \% OMMT clay & 219.29 & 13.87 & 179.09 & 9.77 \\
\hline
\end{tabular}


With the incorporation of OMMT nanoclays, there was a considerable increase in the $\mathrm{Xc}$ of the blend matrix, which indicates that the clay particles act as a nucleating agent in crystallisation process of the PBT matrix there by increasing the crystallinity content. Similar observations have also been reported ${ }^{84}$ where in the effect of organo clay on PP/organo clay/elastomer ternary blends has been investigated.

\section{3. Dynamic mechanical analysis, DMA}

DMA has emerged out as one of the most powerful tools available for the study of the behaviour of plastic materials. DMA gives the fundamental aspects of morphological structure of polymer.

\section{3. 1. Effect of loading clay with PBT-PC 80-20 blend on storage modulus}

Table 6 and Fig. 5 gives the DMA data of PBT-PC 80-20 blend nanocomposites with storage modulus. A gradual decline in E' with increase in temperature was observed in all the cases. In the case of PBT-PC 80-20 blend, the storage modulus decreases from the pure PBT matrix. The low storage modulus indicates that the material is easily deformed by an applied load. However, it can be seen that with the addition of $5 \%$ weight ratio of MMT clay into the PBT-PC 80-20 blend matrix, results in an increase in storage modulus. On the addition of $5 \%$ weight ratio of OMMT clay to PBT-PC 80-20 weight ratio, the storage modulus increases considerably. The elastic component $E^{\prime}$ is a measure of load bearing capacity of a material and is analogous to the flexural modulus determined in accordance with ASTM D 790. It is evident that addition of MMT clay as well as OMMT clay increases the modulus of virgin matrix and PBT-PC 80-20 blend in the entire experimental range.

Table 6. DMA data of PBT, PBT-PC 80-20 blend and their nanocomposites.

\begin{tabular}{|l|c|c|c|}
\hline \multicolumn{1}{|c|}{ Polymer type } & $\begin{array}{c}\text { Storage } \\
\text { modulus E, } \\
\mathrm{MPa}\end{array}$ & $\begin{array}{c}\text { Loss modulus } \\
\mathrm{Tg} \text { temperature } \\
{ }^{\circ} \mathrm{C}\end{array}$ & $\begin{array}{c}\text { Tan delta peak } \\
\text { temperature }{ }^{\circ} \mathrm{C}\end{array}$ \\
\hline Pure PBT & 2125 & 68.04 & 82.16 \\
\hline PBT-PC 80-20 & 1915 & 67.72 & $133.33,75.65$ \\
\hline PBT-PC 80-20+5\% MMT & 2250 & 81.15 & 98.81 \\
\hline PBT-PC 80-20+5\% OMMT & 2330 & 77.37 & 93.52 \\
\hline
\end{tabular}

This indicates that reinforcing effect imparted by nanoclays with high aspect ratio of clay platelets and degree of dispersion of clay particles allowed a greater degree of stress transfer at the interface ${ }^{85}$. The significant improvement in storage modulus by nanoclays is also due to the stiff nature of clay filler and the phenomena commonly observed with other exfoliated polymer/clay systems ${ }^{86,87,88}$. OMMT clay exhibited the maximum storage modulus value, thus confirming the effective dispersion of OMMT nanoclays within the blend matrix than MMT nanoclays. 


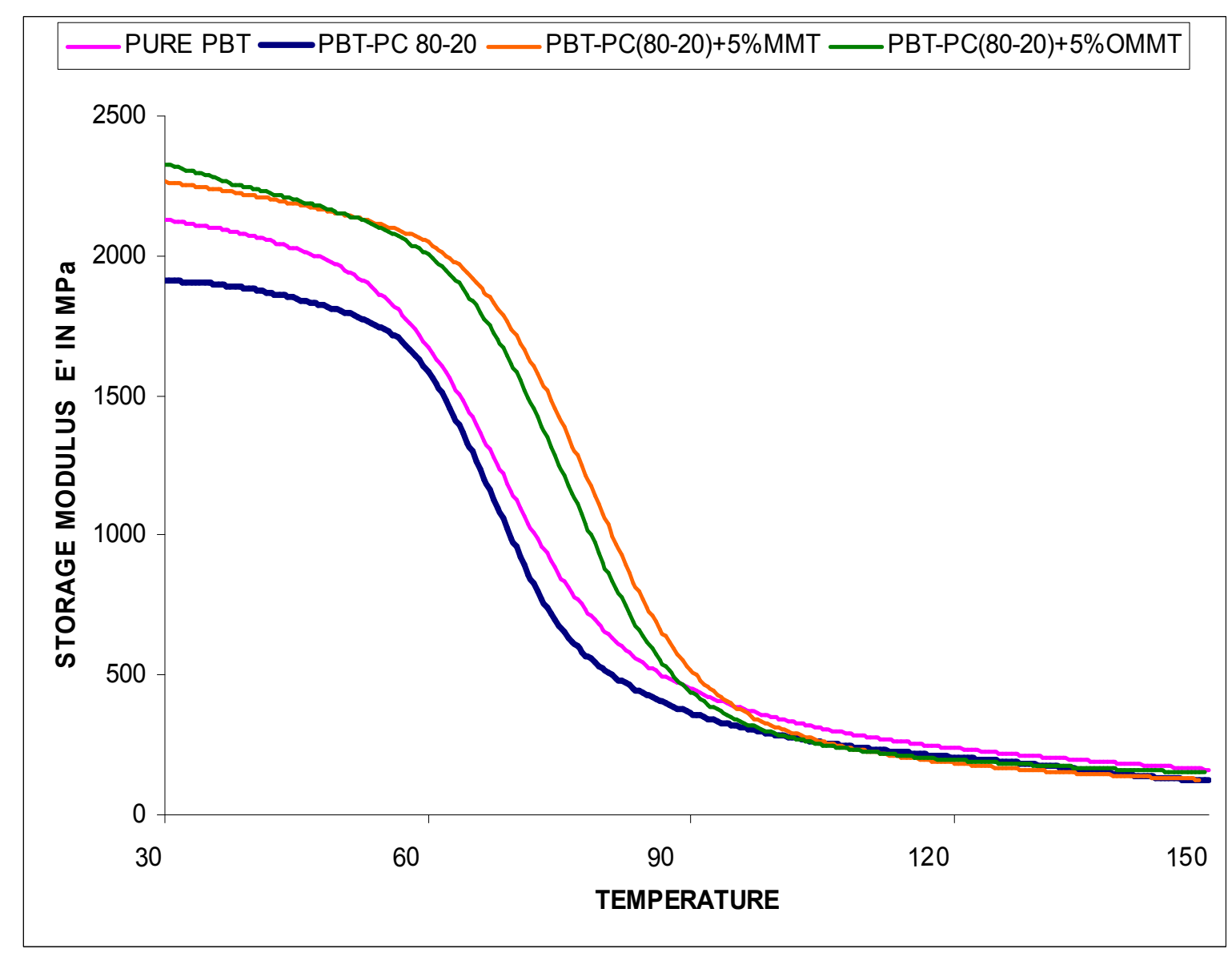

Fig. 5. DMA of PBT, PBT - PC 80-20 and their clay nanocomposites.

\section{3. 2. Effect of loading clay with PBT-PC 80-20 blend on loss modulus}

When blending two polymers, the resulting blend may form a single or multiphase mixture. For a miscible system, only one Tg is observed and it is generally between the Tg's of the pure components. A partially miscible system exhibits two Tg's that are slightly shifted from that of the neat components. An immiscible system also exhibits two Tg's but exactly that of the neat components.

The peak of the loss modulus is conventionally identified as the $\mathrm{Tg}$, even though the DMA plot clearly shows that the transition is a process that spans a temperature range. The loss modulus provides the best agreement with determinations made by other thermal analysis methods and ASTM has recently codified this into D-4065.

The loss modulus curves of pure PBT, PBT-PC 80-20 blend and the nanocomposites are illustrated in Fig. 6 exhibits only one relaxation peak in each but PBT-PC 80-20 E" curve shows two relaxation peaks. Thus, PBT-PC is partially miscible but the miscibility is improved on the addition of clay. A single Tg in the DMA of the clay incorporated nano composites confirms that clay acts as compatibiliser.

The addition of $20 \% \mathrm{PC}$ in weight ratio lowers the Tg value marginally but addition of clay increases the $\mathrm{Tg}$ considerably. The increase in storage modulus and $\mathrm{Tg}$ values due to clay particles could be attributed to the hindrance of macro molecular mobility of polymer chains caused by the well dispersed MMT clay and OMMT clay silicate layers in the PBTPC matrix as proven in other polymer/clay systems ${ }^{89,90}$. Nayak et al., have reported that the 
enhancement in Tg suggests an increase in the thermal stability of the blend as well as its nanocomposites ${ }^{86}$.

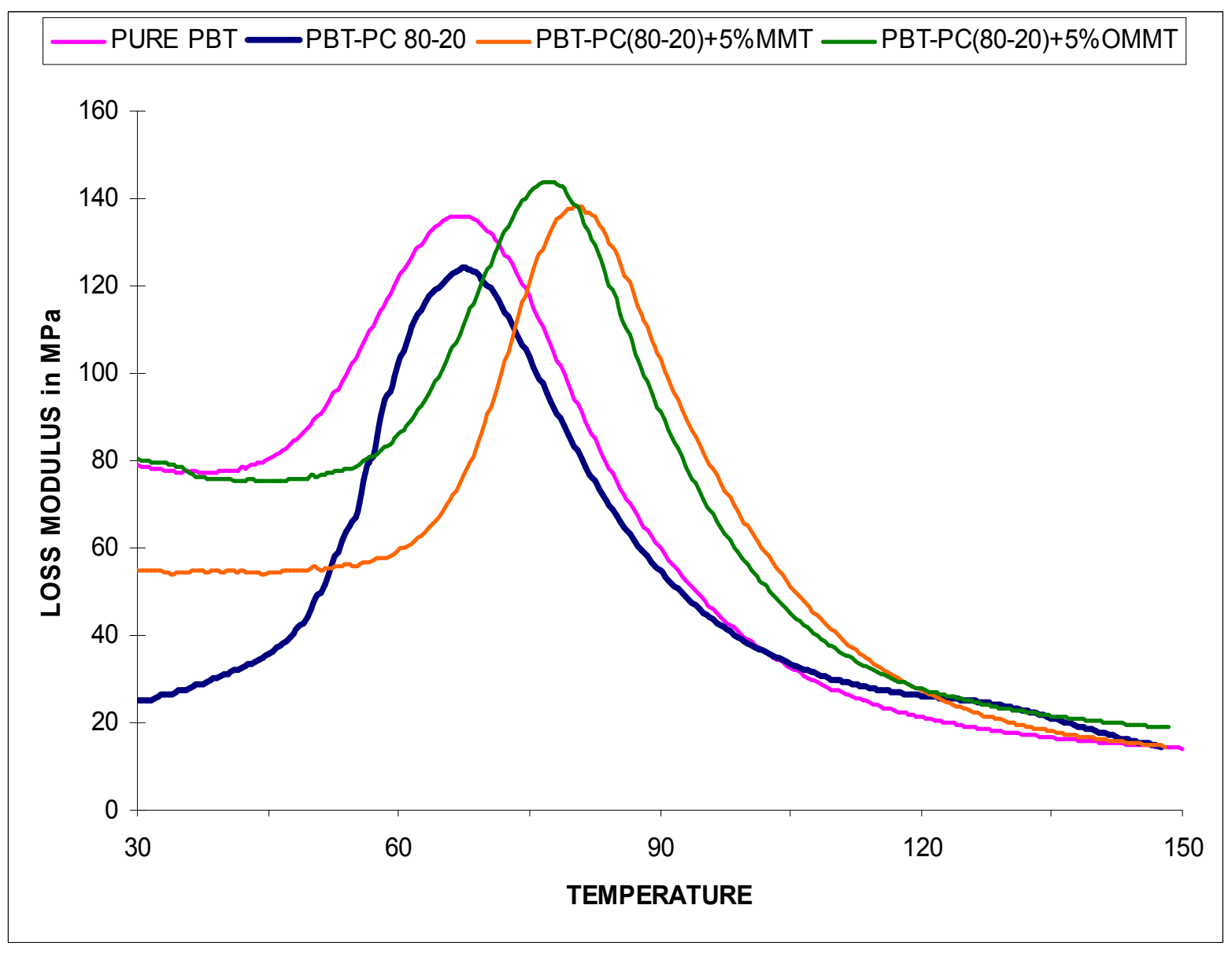

Fig. 6. DMA of PBT, PBT - PC 80-20 and their clay nanocomposites.

The shift in Tg to higher temperature by about $10^{\circ} \mathrm{C}$, confirms that small amount of nano particles can effectively restrain the movements of polymeric chain segments which in turn affects the toughness of matrix especially in the regions near $\mathrm{Tg}^{91}$. Nanocomposites exhibiting a higher $\mathrm{Tg}$ is probably attributed to the large surface area of the nanoclays, which results in efficient contact with large amount of polymer chains thereby preventing the segmental motion of the latter ${ }^{92}$. At higher temperature, many polymeric chains will not experience softness due to the hard barrier phase. Thus, improvement in Tg suggests an increase in the thermal stability of the blend as well as its nanocomposites.

\section{MORPHOLOGY STUDIES-EFFECT OF LOADING CLAY WITH PBT-PC 80-20 BLEND}

$\mathrm{XRD}$ and TEM have been regarded as complementary in characterising the micro structure of the PLS nanocomposites.

The DMA and DSC results clearly indicate that clay has played role of compatibilisers in the partially miscible PBT-PC blend. The wide angle X-ray diffraction patterns of MMT clay, Fig. 7 shows a diffraction peak at $2 \theta=8.025^{\circ}$ corresponding to a d- 
spacing of $1.2 \mathrm{~nm}$. The XRD pattern of organically modified clay OMMT given in Fig 8, exhibits a reflection peak at $2 \theta=4^{\circ}$ with a d-spacing of $2.42 \mathrm{~nm}$.

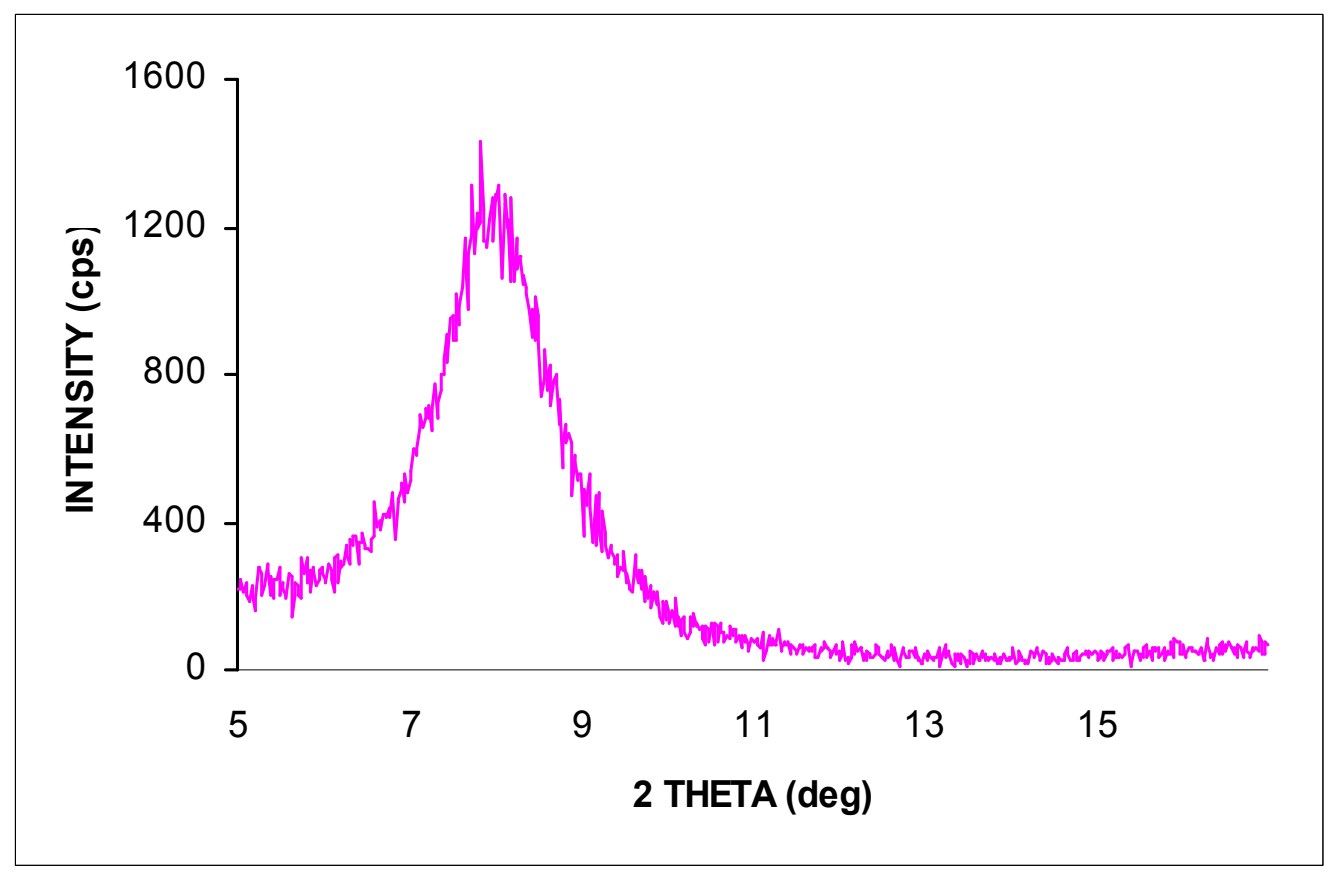

Fig. 7. XRD of MMT clay.

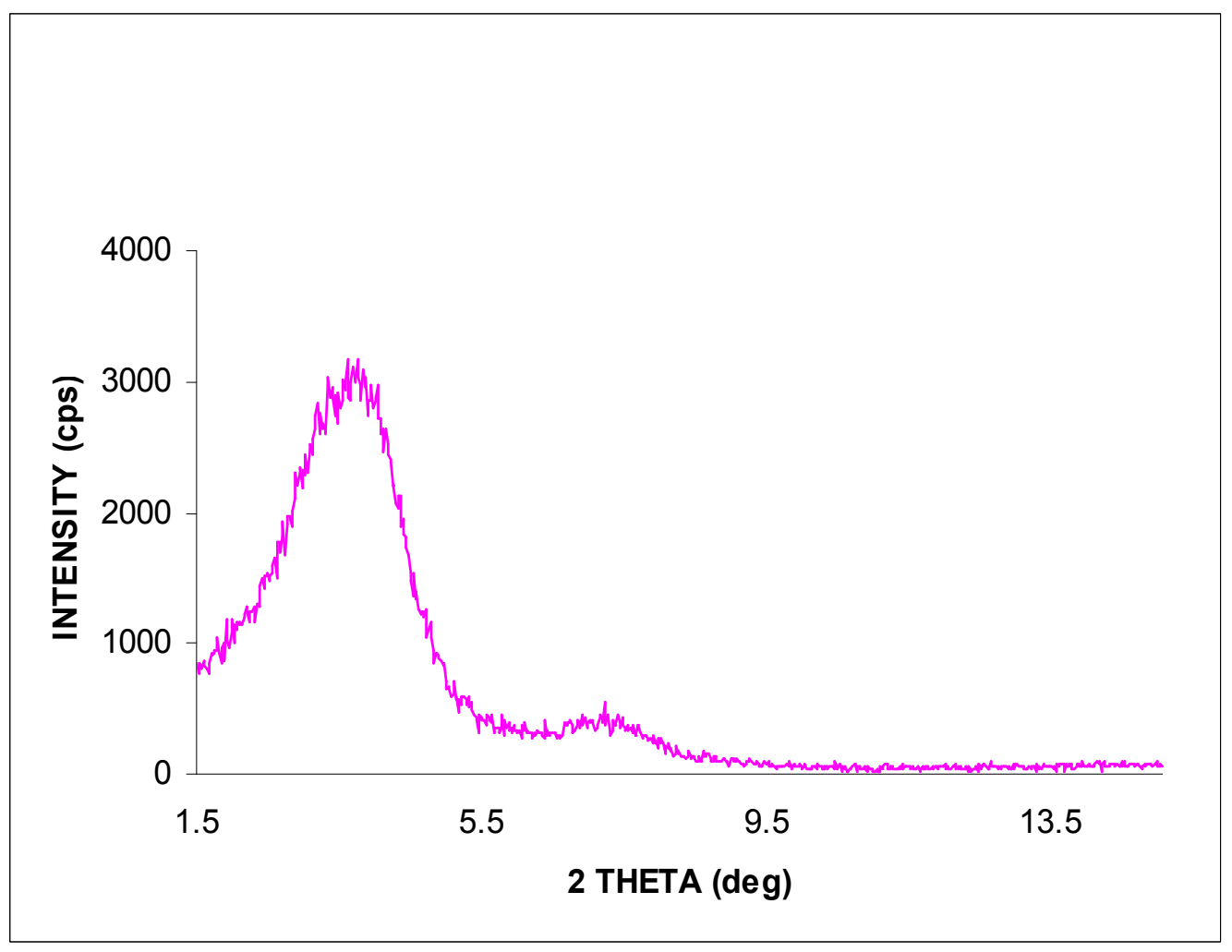

Fig. 8. XRD of OMMT clay. 
X-ray diffraction patterns of PBT-PC 80-20 blend nanocomposites prepared using MMT and OMMT clays at $3 \%$ and $5 \%$ weight ratio loading, Fig. 9 and Fig. 10 did not show any peak at $2 \theta$ less than $10^{\circ}$, indicating the absence of intercalated clay structure in the film ${ }^{93}$. The absence of basal plane peaks indicates the delamination and dispersion of the clay nano layers within the PBT-PC matrix ${ }^{94}$. This suggests that the clay has exfoliated and dispersed in the PBT-PC matrix.

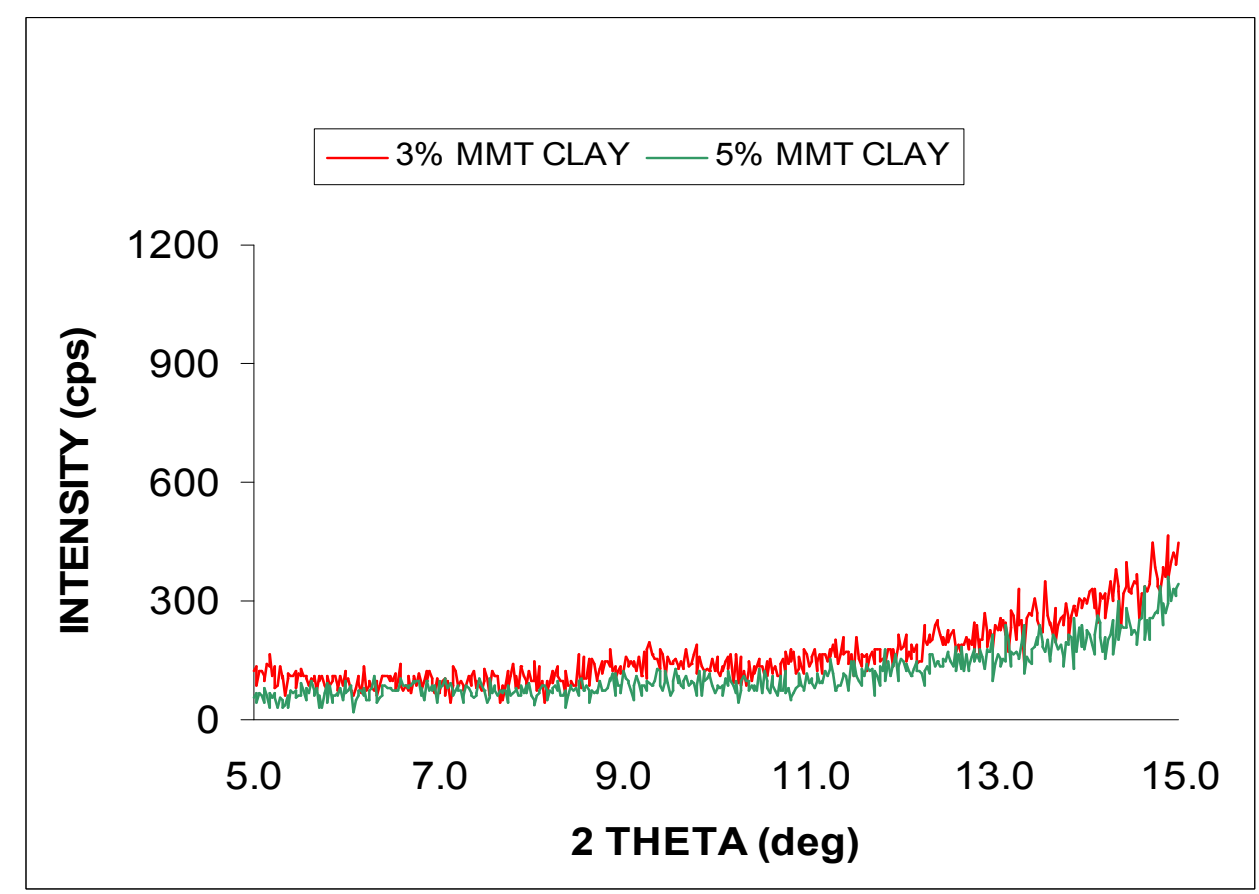

Fig. 9. XRD of PBT-PC 80-20 blend with MMT clay.

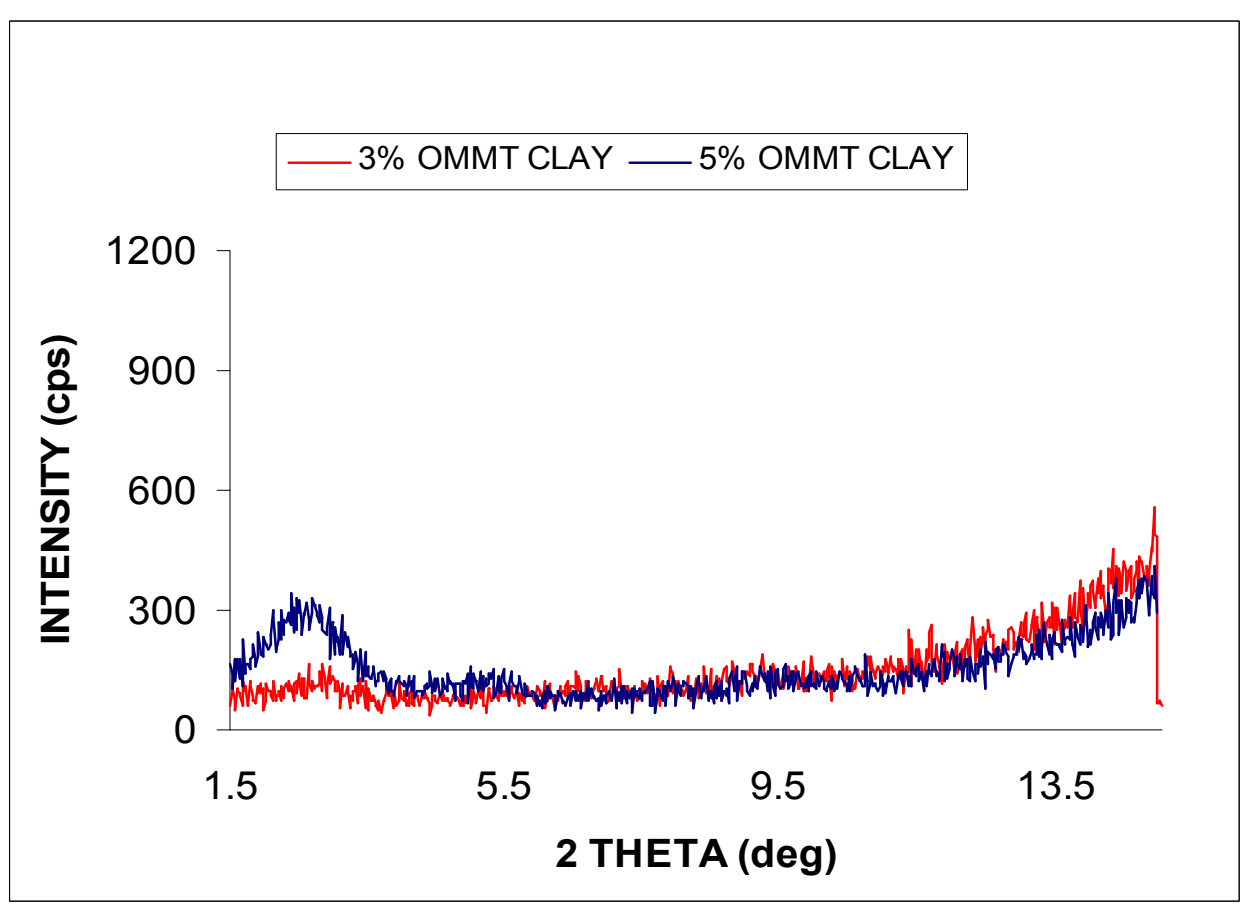

Fig. 10. XRD of PBT-PC 80-20 blend with OMMT clay. 
It should be noted that a few completely exfoliated PLS nanocomposites exhibit no peak, but instead display a gradual increase in the diffraction intensity towards low diffraction angles ${ }^{95,96}$, this is not always the case, however. In fact, it was extensively reported that some PLS nanocomposites show featureless XRD patterns when they exhibit exfoliated or delaminated structures ${ }^{97-102}$. Vain et al., ${ }^{103}$ and Galgali et al., ${ }^{104}$ also observed featureless XRD patterns even for partially exfoliated nano structures.

The TEM micrographs Fig. 11 and 12 of the PBT-PC 80-20 with $5 \%$ OMMT clay shows that, most clay layers are well exfoliated into individual layers and the layers with larger dimensions retained intercalated structure. OMMT clay exhibits enhanced dispersion of the clay platelets and acts as reinforcing filler.

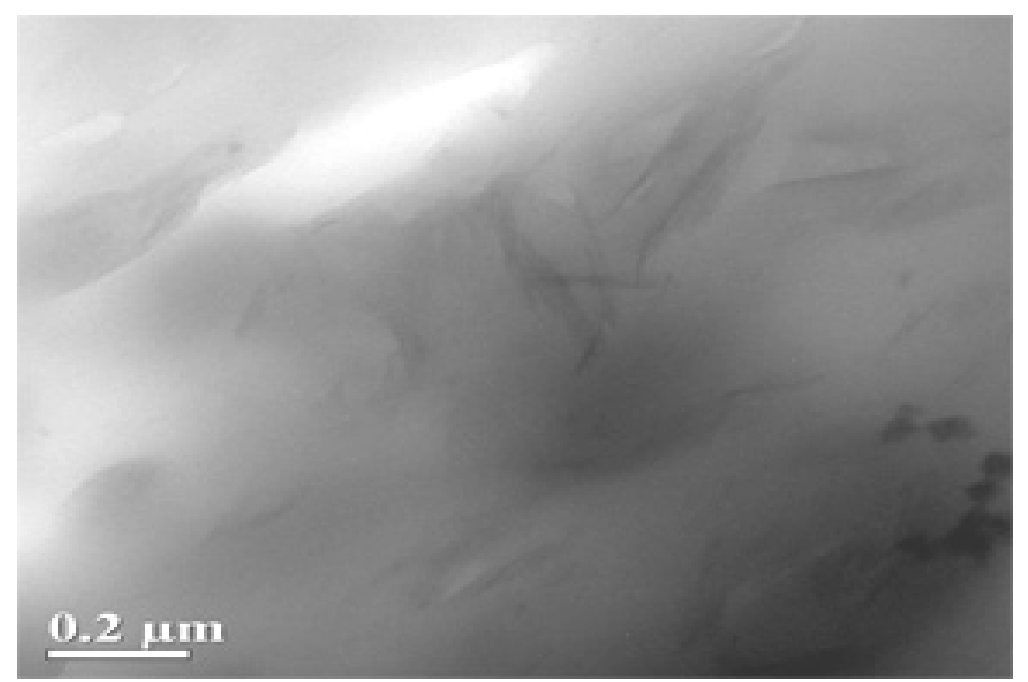

Fig. 11. TEM micrograph of PBT-PC 80-20 with $5 \%$ MMT clay.

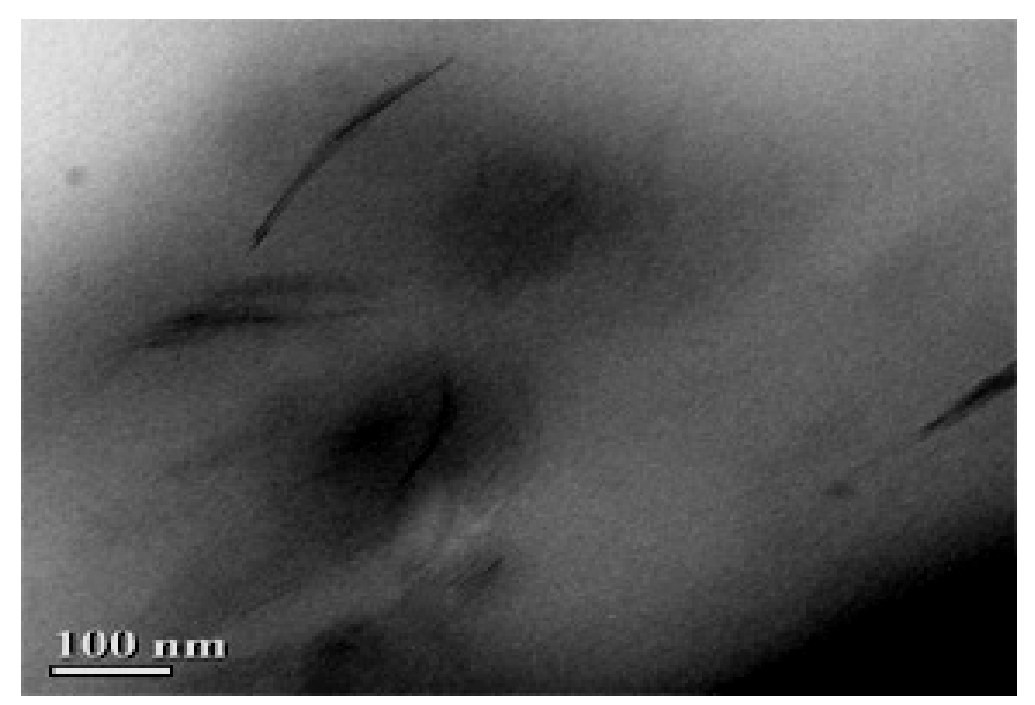

Fig. 12. TEM micrograph of PBT-PC 80-20 with $5 \%$ OMMT clay. 
In the case of PBT-PC/MMT nanocomposites, the dispersion of the clay particles was poor. However, there are some finely exfoliated clay layers and some unexfoliated individual clay particles are seen. The polar interactions between the polymer and clay conglomerate to form aggregates ${ }^{105}$. Conversely, the nanocomposites prepared using organically modified OMMT clay depicts well dispersed exfoliated morphology of the clay layers. Modification of clay with organic layer, lowered electrostatic interactions between the clay layers by enhancing their intra gallery spacing thus facilitating exfoliation and efficient dispersion of the clay ${ }^{105-107}$.

\section{CONCLUSION}

- $\mathrm{PBT} / \mathrm{PC}$ blend nanocomposites were prepared by employing melt compounding technique.

- Incorporation of PC to the PBT matrix increases the impact strength of the virgin matrix and tensile and flexural properties. However, incorporation of OMMT and MMT nanoclays along with PBT/PC increases impact strength without sacrificing the tensile and flexural property in the blend matrix.

- Blending of PBT with PC and nanoclay accelerates the crystallisation process. In case of $\mathrm{PBT} / \mathrm{PC}$ blend nanocomposites, the storage modulus increased with the incorporation of the nanoclays.

- A slight improvement in the thermal stability of the PBT-PC 80-20 was noticed after the incorporation of the nanoclay.

- XRD and TEM clearly show that clay has exfoliated and dispersed in PBT-PC blend matrix.

\section{References}

[1] Mishra S. P., Deopure L., Polymer Bull. 26 (1985) 5.

[2] Yu Y., Choi K., Polym. Engg. Sci. 37 (1997) 91.

[3] Nabisaheb D. Jog J. P., Polym. Sci. Part B, Polym. Phys. 37 (1999) 2439.

[4] Avramova N., Polymer 36 (1995) 801.

[5] Wfer J. M., US Patent 485 (1984) 212.

[6] Pratt C. F., Phadke S. V., Oliver E., US Patent 965 (1990) 111.

[7]. Okada A., Kawasumi M., Usuki A., Kojima Y., Kurauchi T., Kamigaito O., Synthesis and properties of nylon-6/clay hybrids, In: Schaefer D. W., Mark J. E., Ed., Polymer based molecular Composites, MRS Symposium Proceedings, Pittsburgh, 171 (1990) 45.

[8]. Giannelis E. P., Adv. Mater 8 (1996) 29.

[9]. Giannelis E. P., Krishnamoorti R., Manias E., Adv. Polym. Sci. 138 (1999) 107.

[10]. LeBaron P. C., Wang Z., Pinnavaia T., J. Appl. Clay Sci. 15 (1999) 11.

[11]. Vaia R. A., Price G., Ruth P. N., Nguyen H. T., Lichtenhan J., Appl. Clay Sci. 15 (1999) 67. 
[12]. Biswas M., Sinha Ray S., Adv. Polym. Sci. 155 (2001) 167.

[13]. Giannelis E. P., Appl. Organomet Chem. 12 (1998) 675.

[14]. Xu R., Manias E., Snyder A. J., Runt J., Macromolecules 34 (2001) 337.

[15]. Bharadwaj R. K., Macromolecules 34 (2001) 1989.

[16]. Messersmith P. B., Giannelis E., J. Polym Sci., Part A: Polym. Chem. 33 (1995) 1047.

[17]. Yano K., Usuki A., Okada A., Kurauchi T., Kamigaito O., J Polym Sci., Part A: Polym Chem. 31 (1993) 2493.

[18]. Kojima Y., Usuki A., Kawasumi M., Fukushima Y., Okada A., Kurauchi T., Kamigaito O., J. Mater Res. 8 (1993) 1179.

[19]. Gilman J. W., Kashiwagi T., Lichtenhan J. D., SAMPE J. 33 (1997) 40.

[20]. Gilman J. W., Appl. Clay Sci. 15 (1999) 31.

[21]. Dabrowski F., Bras M. Le, Bourbigot S., Gilman J. W., Kashiwagi T., Proceedings of the Eurofillers' 99, Lyon-Villeurbanne, France, September 1999.

[22]. Bourbigot S., LeBras M., Dabrowski F., Gilman J. W., Kashiwagi T., Fire Mater. 24 (2000) 201.

[23]. Gilman J. W., Jackson C. L., Morgan A. B., Harris Jr. R., Manias E., Giannelis E. P., Wuthenow M., Hilton D., Phillips S. H., Chem. Mater. 12 (2000) 1866.

[24]. Sinha Ray S., Yamada K., Okamoto M., Ueda K., Nano Lett. 2 (2002) 1093.

[25]. Lim J. W., Hassan A., Rahmat A. R., Wahit M. U., Polym. Int. 55 (2006) 204.

[26]. Wu Dezhen, Wang Xiaodong, Song Yongzhi, Jin Riguang, J. Appl. Polym. Sci. 92 (2004) 2714.

[27]. Alexandre Michael, Dubois Philippe, Sun Tao, Garces M. J., Jerome Robert, Polymer 43 (2002) 2123.

[28]. Mark H. F., Bikales N. M., Overberger C. G., Menges G., Kroschuritz J. I., Encyclopedia of polymer Science and Engineering, New York, Wiley, 1986, 12.

[29]. Van Berkel R. W. M., Van Hartigsveldt E. A. A., Van der Sluijs C. L., In: Olalrisi O., Ed. Handbook of thermoplastic, New York, Marcel Dekker, 1997, Ch. 20.

[30]. Jadhav J. Y., Kantor S.W., Thermoplastic Polyesters in encyclopedia of Polymer Science and engineering, New York, $2^{\text {nd }}$ Ed,Wiley, 1985, 12.

[31]. Flexman E. A., Polym. Engg. Sci. 19 (1979) 564.

[32]. Hourston D. J., Lang S., in Rubber Toughened Engineering Plastics, Ed. A. A. Collyer, Chapman and Hall, London 1994.

[33]. Gaymans R. J., In: Paul D. R., Bucknall C. B., Editors. Polymer blends, New York, Wiley, 2000, 2, Ch. 25.

[34]. Kojima Y., Usuki A., Kawasumi M., Okada A., Fukushuma Y., Kurauchi T., Kamigaito O., J. Mater Res. 8 (1993) 1185. 
[35]. Kim G. M., Lee D. D., Hoffmann B., Kressler J., Stoppelmann G., Polymer 42 (2001) 1095.

[36]. Cho J. W., Paul D. R., Polymer 42 (2001) 1083.

[37]. Xu X., Qutubuddin S., Polymer 42 (2001) 807.

[38]. Chen G. M., Liu S. H., Zhang S. F., Qi Z. N., Macromol. Rapid Comm. 21(11), (2001) 746.

[39]. Vaia A. R., Jandt K. D., Giannelis E. P., Chem. Mater. 8 (1996) 2628.

[40]. Reichert P., Nitz H., Klinke S., Brandsch R., Thomann R., Mulhaupt R., Macromol. Mater. Engg. 275(2), (2000) 8.

[41]. Galgali G., Ramesh C., Lele A., Macromolecules 34 (2001) 852.

[42]. Kawasumi M., Hasegawa N., Kato M., Usuki A., Okada A., Macromolecules 30 (1997) 6333.

[43]. Usuki A., Kato M., Okada A., Kurauchi J., J. Appl. Polym. Sci. 63 (1997) 137.

[44]. Ko M. B. Kor, Polymer J. 8 (2000) 186.

[45]. Zanetti M., Camino G., Thomann R., Miilhaupt R., Polymer 42 (2001) 4501.

[46]. Li X. C., Ha C. S., Journal Appl. Polymer Sci. 87 (2003) 1901.

[47]. Chen W., Xu Q., Yuan R. Z., Mater. Sci. Engg. B77 (2000) 15.

[48]. Wahrmund D. C., Paul D. R., Barlow J. W., J. Appl. Polym. Sci. 22 (1978) 2155.

[49]. Wilkinson A. N., Tattum S. B., Polymer 38 (1997) 1923.

[50]. Tattum S. B., Cole D., Wilkinson A. N., J. Macromol. Sci.-Phys. B 39(4), (2000) 459.

[51]. Hobbs S. Y., Groshans V. L., Dekkers M. E. J., Shultz A. R., Polymer Bulletin 17 (1987) 335 .

[52]. Hanrahan B. D., Angeli S. R., Runt J., Polymer Bulletin 14 (1985) 399.

[53]. Hobbs S. Y., Dekkers M. E. J., Watkins V H, Polymer Bulletin, 1987, 17, 341.

[54]. Sanchez P., Remiro P. M., Nazbal J., J. Appl. Polym. Sci. 50 (1993) 995.

[55]. Delimoy D., Bailly C., Devaux J., Legras J., Polym. Engg. Sci. 28 (1988) 104.

[56]. Devaux J., Godard P., Mercier J. P., J. Polym. Sci. 20 (1982) 1881.

[57]. Delimoy D., Goffaux B., Devaux J., Legras R., Polymer 36 (1995) 3255.

[58]. Vishu Shah, Handbook of Plastics Testing Technology, John Wiley, New York, 1984, 8.

[59]. Rodriguez F., Principles of Polymer Systems, McGraw-Hill, New York, 1970, Ch.8.

[60]. Dekkers M. E. J., Hobbs S., Watkins V. H., J. Mater. Sci. 23 (1988) 1225.

[61]. Archondouli P. S., Kalfogolu N. K., Polymer 42 (2001) 3489.

[62]. Yonglai Lu, Ying Zhang, Guo dav Zhang, Mingshu Yang, Shouke Yan, Deyan Shen, Polymer 45 (2004) 8999.

[63]. Nayak K. S., Int. J. of Plastics Tech. 12 (2008) 1027. 
[64]. Chavaria F., Paul D. R., Polymer 45 (2004) 8501.

[65]. Vishu Shah, Handbook of Plastics Testing Technology, John Wiley, New York, 1984, 241.

[66]. Brydson J. A., Plastics Materials, $7^{\text {th }}$ Edn. Butterworth and Heinemann, Oxford, 2005, 73.

[67]. Ahn B. D., Kim S. H., Kim Y. H., Yand I. S., J. Appl. Polym. Sci. 82 (2001) 2008.

[68]. Wunderlich B., Thermal Analysis, Academic Press, New York, 1990.

[69]. Brown M. E., Gallagher P. K., Handbook of Thermal Analysis, Elsevier, Amsterdam, 2003, 2.

[70]. Haines P. J., Thermal Methods of Analysis, Principles, Applications and Problems, Blackie Academic Professional, London, 1995.

[71]. Gallagher P. K., Gyorgy B. M., Thermal Analysis, Basal: Birkhauser, 1980, 1.

[72]. Reading M., Thermal Analysis-Techniques and Applications, Royal Soc. of Chemistry, 1992.

[73](68). Wunderlich B, Thermal Analysis, Academic Press, New York, 1990.

[74]. Kemp R. B., Handbook of Thermal Analysis and Calorimetry, Elsevier, Amsterdam, $1998,1$.

[75]. Duvai C., Inorganic Thermo gravimetric Analysis, Elsevier, Amsterdam, 1963.

[76]. Alexander M., Dubois P., Mater. Sci. Engg. 28 (2000) 1.

[77]. Gilman J. W., Jackson C. L., Morgan A. B., Harris R., Manias E., Giannelis E. P., Wuthenow M., Hilton D., Philips S. H., Chem. Mater. 12 (2000) 1866.

[78]. Illers K. H., Colloid Polym. Sci. 258 (1980) 117.

[79]. Chow Wen Shyang, Malaysian Polymer Journal 3(1), (2008) 1.

[80]. Mohd Ishak Z. A., Ariffin A., Senawi R., Europian Polymer Journal 37 (2001) 1635.

[81]. Hage E., Ferrerira L. A. S., Manrich S., Persan L. A., J. Appl. Polym. Sci. 71 (1999) 423.

[82]. Sun S. L., Xu X. Y., Yang H. D., Zhang H. X., Polymer 46 (2005) 7632.

[83]. Delimoy D., Goffaux B., Devaux J., Legras R., Polymer 36 (1995) 3255.

[84]. Li Y. M., Mechanical Behaviour of Multiphase, Ph.D Thesis, Texas, 2001.

[85]. Chow W. S., Mohd Ishak Z. A., Ishiaku U. S., Karger Kocsis J., Apostolov A. A., J. Appl. Polym. Sci. 91 (2004) 175.

[86]. Sanjay K. Nayak, Int. J. of Plastics Tech. 12 (2008) 1027.

[87]. Smitha Mohanty, Samal S., Tripathy Y. K., Nayak S. K., Verma S. K., Int. J. of Plastics Tech. 9 (2005) 436.

[88]. Tianxi Liu, Kian Ping Lim, Wuiwui Chauhari Tjiu, Pramoda K. P., Zhi-Kuan Chen, Polymer 44 (2003) 3529. 
[89]. Starkweather H. W., Macromolecules 21 (1988) 1798.

[90]. Chen L. P., Yee A. F., Goetz J. M., Schaefer J., Macromolecules 31 (1998) 5371.

[91]. Di Y. W., Iannance S., Di M. E., Nicolais L., J. Polym. Sci. Polym. Phys. 41 (2003) 670.

[92]. Riva A., Zanetti M., Braglia M., Camino G., Falqui L., Polym. Degra. Stab. 77 (2002) 299.

[93]. Hui Zhang, Zhong Zhang, Jing-Lei Yang, Klaus Friedrich, Polymer 47 (2006) 679.

[94]. Chang J. H., Seo D. B. S., Wang H., Polymer 43 (2002) 2969.

[95]. Morgan A. B., Gilman J. W., J. Appl. Polym. Sci. 87 (2003) 1329.

[96]. Liu T., Lim K. P., Tjiu W. C., Pramoda K. P., Chen Z. K., Polymer 44 (2003) 3529.

[97]. Usuki A., Kawasumi Y., Kojima M., Fukushima Y., Kurauchi T., Kamigaito D., J. Mater. Res. 8 (1993) 1179.

[98]. Kawasumi M., Hasegawa N., Kato M., Usuki A., Okada A., Macromolecules 30 (1997) 6333.

[99]. Fu X., Qutubuddin S., Polymer 42 (2001) 807.

[100]. Lü J. K., Ke Y. C., Qi Z. N., Yi S., J. Polym. Sci., Part B: Polym. Phys. 39 (2001)

115

[101]. Alexandre M., Dubois P., Mater. Sci. Engg. 28 (2000) 1.

[102]. LeBaron P. C., Wang Z., Pinnavaia T. J., Appl. Clay Sci. 15 (1999) 11.

[103]. Agag T., Takeichi T., Polymer 41 (2000) 7083.

[104]. Chen T. K., Tien Y. I., Wei K. H., Polymer 41 (2000) 1345.

[105]. Vain R. A., Jandt K. D., Kramer E. J., Giannelis E. P., Chem. Mater. 8 (1996) 2628.

[106]. Galgali G., Ramesh C., Lele A., Macromolecules 34 (2001) 852.

[107]. Paul D. R., Newman S., Polymer Blends, Academic Press, New York, 1978. 